\title{
O ESTÁGIO SUPERVISIONADO NA FORMAÇÃO DO PROFESSOR DE MATEMÁTICA: REFLETINDO SOBRE AS EXPERIÊNCIAS
}

\begin{abstract}
Resumo
Este trabalho constitui-se no relato da experiência de organização do Estágio Supervisionado do curso de licenciatura em Matemática desenvolvida no Instituto de

Wellington Lima Cedro

Instituto de Matemática

Universidade Federal de Goiás

Matemática da Universidade Federal de Goiás (IME/UFG). A partir da promulgação de uma série de diretrizes legais pelo Conselho Nacional de Educação, a formação docente passa a ser compreendida como um processo permanente que envolve tanto a valorização da identidade do professor como da sua profissionalidade. Nesse processo de formação docente, um dos elementos curriculares que se coloca como imprescindível é o estágio, compreendido agora como um campo de conhecimento, suplantando o tradicional reducionismo ao qual era submetido. Atendendo a estas novas demandas, o IME/UFG reelaborou a proposta de organização do Estágio Supervisionado. O desenvolvimento desta proposta de organização vem oferecendo a nossa comunidade de futuros professores, a oportunidade de colocar-se em um movimento de ação e reflexão sobre a docência.
\end{abstract}

Palavras-chave: Estágio supervisionado; Formação de professores; Educação Matemática.

Olh@res, Guarulhos, v. 1, n1, p. 284-302, maio 2013. 


\title{
THE SUPERVISED INTERNSHIP IN MATHEMATICS \\ TEACHER EDUCATION: REFLECTING ABOUT THE EXPERIENCES
}

\begin{abstract}
This work constitutes the report on the experience of organizing the supervised internship the degree course in mathematics developed in the Instituto de Matemática of Universidade Federal de Goiás (IME/UFG). Since the enactment of a series of legal guidelines by the National Council of Education, teacher education is to be understood as an ongoing process that involves both the development of identity of the teacher as their professionalism. In this process of teacher education, one of the curricular elements that arises as essential is the internship, which happens to be designed as a field of knowledge, supplanting the traditional reductionism to which he was subjected. Given these new demands, the IME/UFG reworked the supervised internship's organization. The development of this proposed organization of internships has been providing our community of preservice teachers the opportunity to put yourself in the movement of reflection about the teaching.
\end{abstract}

Keywords: Supervised internship; Teacher education;

Mathematics education.

Olh@ res, Guarulhos, v. 1, n1, p. 284-302, maio 2013. 


\section{Introdução}

No contexto atual é evidente que a formação do professor cabe uma grande atenção, sendo necessário encarar este ato de ensinar como aquele que permite ao professor colocar-se na perspectiva daquele que busca a verdade sobre as ações que o formam e que lhe possibilitam formar outros sujeitos. Na busca por estes caminhos, que possam tornar o processo de formação de professores mais significativo, e por consequência adequado as exigências atuais da sociedade, o MEC publicou, há alguns anos, as novas Diretrizes Curriculares Nacionais para a Formação de Professores da Educação Básica nos cursos de Licenciatura Plena. Nesse documento encontra-se um conjunto de princípios, fundamentos e procedimentos que devem ser observados na organização institucional e curricular dos cursos de formação de professores. Dentre estes pontos, destaca-se a importância dada ao estágio, que passa a ser entendido agora como um campo de conhecimento (PIMENTA; LIMA, 2004), suplantando o tradicional reducionismo ao qual era submetido, quando entendido como uma mera atividade prática.

Esse novo caráter dado ao estágio ${ }^{1}$, refletiu-se nos encaminhamentos posteriores do Conselho Nacional de Educação, que indicam a necessidade da elaboração por parte das coordenações dos cursos de licenciatura de projetos de estágio institucionais, que estabeleçam claramente os objetivos e as tarefas de todos os sujeitos envolvidos nesta atividade.

Somando estes fatores a implantação do novo regime dos cursos de graduação na Universidade Federal de Goiás e a consequente estruturação curricular, surge, então, a necessidade da elaboração de um Projeto Pedagógico de Estágio que respondesse as novas exigências da formação do professor.

\footnotetext{
${ }^{1}$ Nos últimos anos, tem-se presenciado uma série de estudos relevantes na discussão do estágio supervisionado, entre eles destacam-se os seguintes: Moura (1999), Pimenta (2005), Pimenta e Lima (2004), Barreiro e Gebran (2006) e Oliveira (2006).

Olh@ res, Guarulhos, v. 1, n1, p. 284-302, maio 2013.
} 
O projeto pedagógico do Estágio Supervisionado do Curso de Licenciatura em Matemática do campus Goiânia indica que os objetivos do Estágio Supervisionado são:

- Integrar o processo de formação do futuro licenciado em Matemática, de modo a considerar o campo de atuação como objeto de análise, de investigação e de interpretação crítica, a partir dos nexos com os demais componentes do currículo;

- Constituir-se como um espaço formativo que atenda as necessidades sociais, preservando os valores éticos que devem orientar a prática profissional;

- $\quad$ Constituir-se como um espaço formativo capaz de desenvolver a autonomia intelectual e profissional, possibilitando ao licenciado em Matemática criticar, inovar, bem como lidar com a diversidade dos contextos; e

- Oferecer uma aproximação e compreensão da realidade profissional.

Considerando estes objetivos, o Estágio Supervisionado no Curso de Licenciatura em Matemática da UFG está estruturado, de acordo com a resolução CEPEC n. ${ }^{\circ} 802$ (UFG, 2006), em duas disciplinas anuais pertencentes ao núcleo obrigatório, tendo cada uma delas 200 h/a de carga horária: Estágio Supervisionado I; e Estágio Supervisionado II.

Com base nesta estrutura, neste texto apresento e discuto o modo como tenho organizado as minhas ações no estágio supervisionado, junto aos futuros professores que ensinam Matemática². Assim, a ideia principal que defendo neste artigo é a que o estágio supervisionado deve ser compreendido como uma atividade (LEONTIEV, 1978, 1983) para os estagiários. As reflexões e vivências serão apresentadas de duas maneiras. Na primeira parte do artigo, abordarei os projetos desenvolvidos no estágio supervisionado I e os trabalhos realizados com os estagiários do estágio

\footnotetext{
${ }^{2}$ Gostaria de esclarecer que sou professor efetivo do IME/UFG e que, no momento deste relato, eu ocupava a função de coordenador do estágio supervisionado do curso de licenciatura em Matemática.

Olh@ res, Guarulhos, v. 1, n1, p. 284-302, maio 2013.
} 
supervisionado II. Na segunda parte do texto, analisarei sucintamente o movimento de ressignificação da atividade pedagógica dos estagiários durante o estágio supervisionado.

\section{O estágio supervisionado I}

A finalidade do Estágio Supervisionado I, segundo as resoluções da UFG, é oferecer a possibilidade ao futuro licenciado em Matemática de colocar-se em situações que combinem a relação teoria-prática, de forma a desenvolver nele a construção de modos de ação que lhe permitam um desenvolvimento adequado da sua práxis educativa.

O Estágio Supervisionado I caracteriza-se pelo desenvolvimento de ações vinculadas a projetos realizados nas mais diversas instituições de caráter educacional ou não-educacional.

Os projetos de estágio são marcados principalmente por:

- Serem condutas organizadas para atingir determinadas finalidades específicas;

- Serem ações de caráter permanente ou eventual; e

- Terem um caráter intervencionista, ou seja, permitirem aos discentes

a intervenção nos ambientes educacionais, possibilitando-lhes uma vivência plena dos espaços de aprendizagem (CEDRO, 2004).

Com essas características, nos últimos anos, tenho coordenado dois projetos de estágio, que tem envolvido estudantes da licenciatura em Matemática, da pós-graduação em Educação Matemática, alunos e professores da Educação Básica.

O primeiro projeto chama-se Matemática no Circo. Ele teve as suas atividades iniciadas em 2009 e apresenta como objetivo principal o desenvolvimento de atividades de ensino de Matemática, marcadas principalmente pela ludicidade (CABRAL; CAMARGO; CEDRO, 2010). As atividades do projeto são realizadas em encontros com duração de cerca 01 hora e 20 minutos, realizados duas vezes por semana. A turma geral-

Olh@ res, Guarulhos, v. 1, n1, p. 284-302, maio 2013. 
mente é formada por cerca de 20 crianças, com idade entre seis e quatorze anos, que cursam do $1^{\circ}$ ao $9^{\circ}$ ano do Ensino Fundamental, sendo todos oriundos da rede pública de ensino. O trabalho tem tido ótimos resultados com as crianças e com os futuros professores. Ao analisar a garotada, percebe-se que o desenrolar das ações do projeto fez com que elas se desenvolvessem, pois "se mostravam mais interessadas em realizar as atividades e, com isso, o rendimento aumentava constantemente, tanto em relação ao conhecimento matemático quanto no aspecto do desenvolvimento pessoal" (CABRAL; CAMARGO; CEDRO, 2010, p.99). Por outro lado, os estagiários têm aprendido a compreender melhor as necessidades das crianças e a organizar as atividades de ensino, permitindo que eles alcancem os seus objetivos como sujeitos que organizam o ensino.

O outro projeto é intitulado Clube de Matemática. Assim como o anterior, o Clube de Matemática surge também a partir de 2009 e é desenvolvido por estudantes do curso de licenciatura em Matemática e também envolve os alunos do ensino fundamental e os professores que ensinam Matemática na rede pública (Figura 1). A finalidade do Clube de Matemática é permitir aos sujeitos envolvidos nas atividades a compreensão do processo de ensino e aprendizagem dos conhecimentos matemáticos por meio de atividades de ensino caracterizadas pela ludicidade.

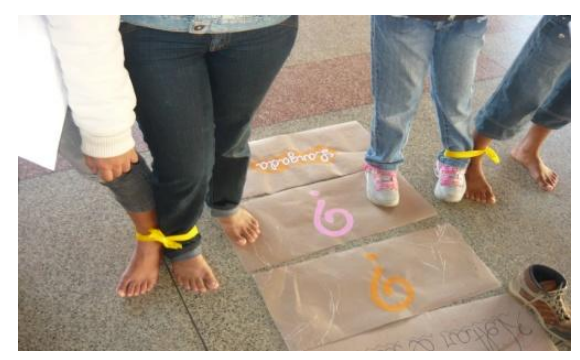

Figura 1: Os estudantes desenvolvendo atividades no Clube de Matemática Fonte: acervo particular.

Os resultados deste projeto têm sido desencadeadores da mudança das práticas dos futuros professores. Em Ribeiro e Cedro (2011, p.8), pode-se constatar isso no discurso de uma estagiária:

Ver no rosto dos alunos o prazer de participar das atividades, perceber a forma como todos respondiam ao que lhes era proposto, tudo isto motivava a querer continuar o projeto e desejar enriquecer os próximos encontros cada vez mais. Como estagiária,

Olh@ res, Guarulhos, v. 1, n1, p. 284-302, maio 2013. 
o crescimento foi formidável, uma vez que proporcionou a emergência de novas concepções sobre a atividade profissional que me aguarda [...].

Já em Oliveira et al (2010, p.9), percebe-se a importância do projeto na transformação dos futuros professores, quando se analisa o relato de uma estagiária.

Com o projeto, aprendemos também a olhar a prática docente de uma maneira diferente, enfatizando o caráter coletivo e principalmente acreditando de que é possível ensinar matemática com atividades que envolvam ao mesmo tempo o prazer e ensino.

Outra constatação é o desdobramento das ações dos futuros professores na escola-campo. Eles perceberam a importância da organização do ensino e do desenvolvimento de atividades de ensino que permitam aos estudantes da educação básica a participação efetiva no processo de aprendizagem.

Já para nós, estagiários, o projeto nos trouxe grande aprendizado. Um dos aspectos mais interessantes foi o fato de que os alunos da escola-campo que não participavam do clube, ao longo do semestre, quiseram participar, pois viram que algo era diferente. Ali os alunos tinham que buscar pela aprendizagem, ou seja, participavam ativamente do processo de aprendizagem, e isso deixava-os animados e interessados. (SILVA; SANTOS; CEDRO, 2010, p.9)

Os resultados provenientes desses dois projetos, desenvolvidos no estágio supervisionado, mostram alguns indícios de como se pode resgatar o papel da escola e torná-la novamente um verdadeiro espaço de aprendizagem, que permita a todos os sujeitos envolvidos no processo educacional a possibilidade do desenvolvimento da crítica, da descoberta e da prática social. Com isso, acredito que poderemos nos aproximar da educação ideal proposta por Vygotsky. Segundo o autor, "uma educação ideal só é possível com base em um ambiente social orientado de modo adequado" (VYGOTSKY, 2003, p.200), ou seja, o desafio que se põe é o de organizar os espaços de aprendizagem de modo que se consiga potencializar o desenvolvimento psicológico dos sujeitos.

Olh@ res, Guarulhos, v. 1, n1, p. 284-302, maio 2013. 


\section{O estágio supervisionado II}

A finalidade do Estágio Supervisionado II, indicada nos documentos oficiais da instituição, é possibilitar ao discente a vivência da profissionalidade docente em toda a sua plenitude, inserindo-o no processo de planejamento, regência, avaliação e reflexão da práxis do professor de Matemática.

O Estágio Supervisionado II caracteriza-se pelo desenvolvimento de atividades que compreendem a pesquisa como princípio metodológico da formação de futuros professores. Desta forma, entende-se que a pesquisa vinculada ao estágio, possui duas facetas principais:

- Uma que permite a análise dos contextos nos quais os estágios são realizados, possibilitando assim a reflexão e a sua ampliação. Isto se dá por meio do desenvolvimento de pesquisas colaborativas (MOURA, 2000), que envolvam tanto os estagiários quantos os pesquisadores;

- $\quad$ E outra que permite "aos estagiários desenvolverem postura e habilidades de pesquisador, a partir das situações de estágio, elaborando projetos que lhe permitam ao mesmo tempo compreender e problematizar as situações que observam" (PIMENTA; LIMA, 2004, p.46).

A ementa da disciplina estágio supervisionado II determina o seguinte sobre a sua finalidade:

O Estágio Supervisionado II caracteriza-se pelo desenvolvimento de atividades que compreendem a pesquisa como princípio metodológico da formação do professor de Matemática. As atividades nas aulas e no estágio supervisionado pretendem levar os alunos, futuros professores, a compreenderem as condições determinantes da aprendizagem e do ensino da Matemática no ambiente escolar. As atividades do Estágio Supervisionado devem ser desenvolvidas em uma escola-campo e devem contemplar os seguintes aspectos: apreensão da realidade da escola-campo; elaboração do projeto de ensino e pesquisa; desenvolvimento do projeto de ensino e pesquisa; e, a elaboração de um relatório final do estágio que apresente a intervenção docente na escola-campo e as contribuições de todo o processo de investigação para a construção pessoal e coletiva da formação docente. (UFG, 2006)

Nesse contexto, a disciplina envolve uma equipe de professores: o professor supervisor do estágio, docente da escola-campo; o professor orientador do

Olh@ res, Guarulhos, v. 1, n1, p. 284-302, maio 2013. 
Relatório do Estágio que assume o papel do Trabalho Final de Curso, docente da instituição; e, por fim, o professor que ministra as aulas teóricas na universidade, que também é do quadro de docentes do Instituto.

A carga horária anual dessa disciplina está dividida da seguinte maneira:

- 100 h/a destinadas à prática na escola-campo, ou seja, o estágio;

- 36 h/a teóricas destinadas à orientação do Trabalho Final do Curso (TFC);

- 64 h/a teóricas desenvolvidas na sala de aula da universidade.

Segundo o Projeto Político-Pedagógico do curso de Matemática, a carga horária prática a ser cumprida na escola-campo deve ser dividida entre as seguintes etapas:

-Etapa 1: Esta etapa compreende o momento de apreensão da realidade da escola-campo. Este é o momento que cabe ao futuro professor caracterizar a escola e a clientela com quem vai trabalhar e delinear a fundamentação teórica de sua proposta pedagógica.

- Etapa 2: Esta etapa caracteriza-se pela cooperação quando o professor da turma e licenciando trabalham juntos na sala de aula. Idealizada para ser desenvolvida nos moldes da monitoria, tem por objetivo preparar o licenciado para assumir futuramente a classe. Ainda faz parte desta etapa a definição da proposta pedagógica a ser vivenciada pelo licenciando no próximo momento.

-Etapa 3: Esta etapa é o momento da execução do plano de ensino, quando o licenciando assume a responsabilidade das diversas atividades que compõem o trabalho docente na sala de aula, sendo responsável pelo desenvolvimento da disciplina, a qual não deve ser inferior a 32 horas/aula.

-Etapa 4: Esta etapa caracteriza-se pela redação final do Trabalho Final de Curso (TFC).

A carga horária teórica que deve ser cumprida na universidade é dividida em dois momentos. O primeiro é destinado à orientação do TFC, que é rea-

Olh@ res, Guarulhos, v. 1, n1, p. 284-302, maio 2013. 
lizada por um professor do quadro docente, não necessariamente vinculado à Educação Matemática. Esse trabalho geralmente é realizado em reuniões semanais. O segundo momento é desenvolvido na sala de aula da universidade em uma aula semanal. Nessas aulas, o foco principal do professor regente e dos estagiários é a elaboração do TFC.

De acordo com a proposta de estágio da instituição, o TFC é um relato do desenvolvimento de uma proposta de ensino de algum conteúdo matemático do ensino fundamental ou médio na escola-campo, pautada pela aplicação de metodologias de ensino. A sua estrutura deve conter as seguintes seções: Introdução; Capítulos: Contextualização; Proposta Pedagógica e Fundamentação teórica; Descrição da ação pedagógica e a análise da ação pedagógica; Conclusão e considerações finais e, Anexos (Planos de aula; Atividades; Avaliações e outros elementos que forem considerados citados no corpo do trabalho).

Com esse direcionamento, todas as atividades realizadas durante as aulas na faculdade têm como principal objetivo fornecer aos discentes elementos para a elaboração da caracterização da escola-campo, da organização da proposta pedagógica, da formatação e da apresentação do relatório final de estágio. Isso ocorre pelo fato de que o TFC produzido pelos estagiários deve ser apresentado a uma banca examinadora, composta por professores da instituição, e constitui-se um dos elementos necessários para a aprovação na disciplina de estágio supervisionado.

Nesta perspectiva, nos últimos anos, tenho orientado uma série de trabalhos (CABRAL; CAMARGO; CEDRO, 2011; ARAUJO; RIBEIRO; CEDRO, 2009; SANTOS; SOUZA; CEDRO, 2008; ALVES; CEDRO, 2007; RIBEIRO; COSTA; CEDRO, 2007) relacionados ao estágio supervisionado que tem como pressuposto básico a pesquisa vinculada ao ensino de matemática na educação básica.

O trabalho de Cabral, Camargo e Cedro (2011) aborda a utilização de jogos como metodologia para o ensino e a aprendizagem de Matemática no Ensino Médio. Esse trabalho cobre uma lacuna, já que grande parte da

Olh@ res, Guarulhos, v. 1, n1, p. 284-302, maio 2013. 
produção acadêmica que versa sobre jogos e atividades lúdicas enfocam o Ensino Fundamental. Deste modo, os autores elaboraram um conjunto de jogos e desenvolveram uma experiência de ensino junto a uma turma do primeiro ano do Ensino Médio de uma escola pública. Por meio dessa experiência, eles obtiveram resultados significativos, como por exemplo, a participação e empenho dos estudantes, e a promoção do diálogo como um dos elementos preponderantes do processo de ensino e de aprendizagem de Matemática na Educação Básica.

Já Araujo, Ribeiro e Cedro (2009) apresentam em seu trabalho uma proposta pedagógica para o ensino do princípio fundamental da contagem. A proposta foi desenvolvida em uma turma do ensino médio de uma escola pública federal e o seu objetivo geral era possibilitar a compreensão dos conceitos matemáticos, utilizando-se de atividades lúdicas. Os principais resultados deste estudo mostram indícios de avanços na apropriação e compartilhamento do conhecimento por parte dos estudantes. A meu ver, isso foi propiciado por meio do desenvolvimento das atividades de ensino que tinham como objetivo a aprendizagem do princípio fundamental da contagem, tendo como base a ludicidade.

Dando continuidade aos trabalhos que envolvem o desenvolvimento de propostas pedagógicas, Santos, Souza e Cedro (2008) organizaram um conjunto de atividades destinadas ao ensino das medidas. Este estudo se caracterizou por enfocar os conceitos relacionados ao sistema de medidas por meio de atividades de ensino, caracterizadas pelo uso de jogos didáticos e pela resolução de situações-problema. O objetivo geral da proposta era que as crianças se colocassem em um movimento que permitissem a elas pensar, usar a intuição, a memória, o raciocínio lógico, a reflexão e a análise para que se apropriassem de uma nova linguagem e explorassem outras possibilidades do pensar matemático. Entre os resultados alcançados, destaca-se a apropriação e a participação significativa dos estudantes em todo o processo de ensino, já que na sua produção percebe-se a elaboração das ideias essenciais relacionados ao ato de medir.

Olh@ res, Guarulhos, v. 1, n1, p. 284-302, maio 2013. 
No trabalho de Ribeiro, Costa e Cedro (2007), encontra-se novamente uma proposta de ensino que enfoca o Ensino Médio. Trata-se de um relato de experiência, desenvolvido com alunos do ensino fundamental de uma escola pública federal, que discute uma proposta de ensino de equações do $1^{\circ}$ grau com uma incógnita. Seu objetivo era o de mostrar a eles as diversas formas de linguagem dentro da álgebra, compreendendo os seus estágios de desenvolvimento na sociedade. As atividades desenvolvidas foram baseadas em uma perspectiva dialógica, que se caracterizou pelo uso de jogos e de softwares pedagógicos. O desenvolvimento das ações pedagógicas da proposta permitiu aos estudantes a compreensão do processo de resolução das equações do $1^{\circ}$ grau com uma incógnita, sem o uso dos algoritmos formais, mas com a sua formalização teórica.

Por fim, o trabalho de Alves e Cedro (2007) apresenta uma experiência de ensino de Matemática desenvolvida no $2^{\circ}$ ano do Ensino Médio da rede Estadual em Goiânia. Utilizando-se de um problema matemático clássico, a duplicação do cubo, conhecido como problema Deliano, desenvolveu-se uma proposta pedagógica que envolveu a apropriação da técnica do origami e a aprendizagem dos conhecimentos relacionados à Geometria Espacial.

\section{Analisando a atividade pedagógica dos estagiários após o}

\section{desenvolvimento das ações de formação no estágio supervisionado}

Com base na análise das experiências relatadas neste artigo, se é capaz de ressaltar que os estagiários encontraram situações, durante o desenrolar do estágio, que possibilitaram a eles a mudança nas suas ações objetivas, portanto, ao cabo deste processo, pode-se evidenciar uma reconstrução da atividade do professor.

Essas mudanças refletem a forma como o trabalho coletivo passa a ser compreendido pelos futuros professores; contudo, esse fenômeno somente ocorre à medida que os indivíduos se apropriam ou elaboram e reorganizam conjuntamente os conhecimentos que surgem nas relações de ensino e

Olh@ res, Guarulhos, v. 1, n1, p. 284-302, maio 2013. 
aprendizagem. Esse conhecimento é inserido no novo modelo de ação pedagógica do professor, o qual é convalidado pelo coletivo de sujeitos que o cerca. A consequência desta afirmação é a importância que o compartilhamento das ações tem para esse processo de formação dos conhecimentos vinculados à docência. Os conhecimentos do professor surgem do diálogo entre o que ele vivencia na realidade da escola e o que ele estudou e aprendeu com os outros indivíduos da prática educativa e com a literatura educacional (FIORENTINI; CASTRO, 2003).

No esquema ${ }^{3}$ a seguir (Figura 2) tenta-se esboçar o compartilhamento das ações utilizando um sistema de atividade expandido. A expansão do sistema encontra-se na inclusão da experiência ou vivência que está atrelado ao indivíduo e das formas de realização que se conectam aos instrumentos e ao objeto da atividade.

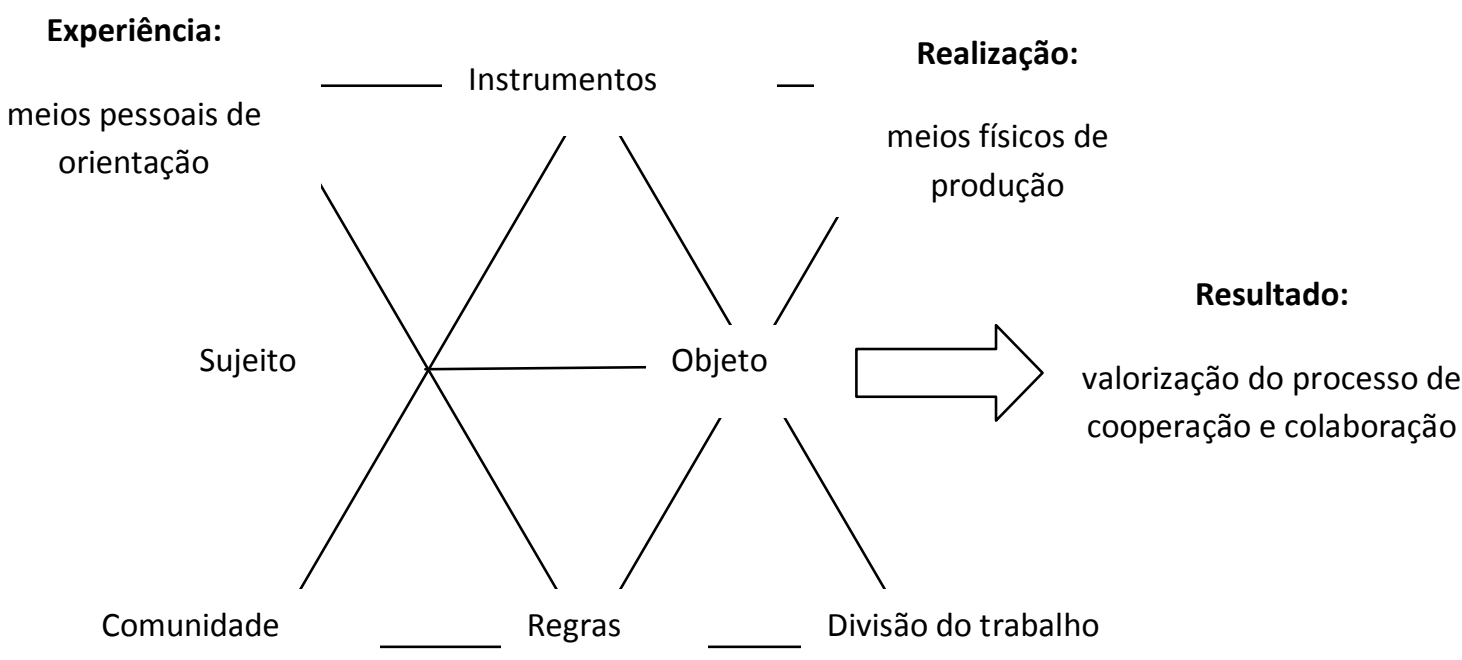

Figura 2: O sistema de atividade para o compartilhamento das ações

Outro aspecto que deve ser destacado nestas experiências é o fenômeno de reconstrução dos significados do conhecimento matemático, que aconteceu por meio da reflexão compartilhada durante o processo de organização do ensino. Este fenômeno permitiu aos futuros professores a apreensão e o estabelecimento de sentido para os conhecimentos inerentes ao fazer pedagógico do docente (LOPES, 2004). A atribuição de novos sentidos ao

\footnotetext{
${ }^{3}$ Adaptado de WELLS (2002).

Olh@ res, Guarulhos, v. 1, n1, p. 284-302, maio 2013.
} 
conhecimento matemático por meio da valorização do lógico-histórico na abordagem do conceito e a tomada de consciência sobre a necessidade de outra forma de organização da aula de Matemática demonstram como estes elementos contribuem para o processo de aprendizagem do futuro docente. Ao prover a prática pedagógica dos estagiários com elementos que pudessem contribuir para o sucesso da aprendizagem dos estudantes, eles acabaram por atribuir uma nova qualidade aos atos e ações realizadas por eles. Em outras palavras, as novas qualidades atribuídas ao objeto do professor, o conhecimento matemático, implicaram uma transformação qualitativa na sua atividade.

Essa mudança deu início a um movimento de formação da atividade pedagógica dos estagiários. Dentro desse fluxo, os futuros professores apropriaram-se de um novo modo de organização do ensino que atendia as demandas inerentes ao processo de humanização e superação da alienação docente; compreenderam que dentro dessa perspectiva, o planejamento assume o papel essencial de organizador da práxis do professor, colocandoo em um patamar mais elevado do que aquele que pretende a burocracia pedagógica; perceberam que as atividades de ensino constituem-se nos instrumentos do professor, e que as ferramentas pedagógicas (livros didáticos, materiais estruturados, jogos, computadores, calculadoras, etc.) não representam a sua essência; compreenderam a função primordial da intencionalidade do professor e dos registros como elementos que contribuem para a avaliação educacional; por fim, tomaram consciência das novas qualidades das relações estabelecidas entre os indivíduos participantes da atividade educativa.

A meu ver, todo esse conjunto de elementos que caracterizam uma visão de organização do ensino viabiliza a apropriação dos conhecimentos necessários para a transformação da atividade docente. Esse processo somente ocorre quando há convergência entre os motivos e as ações desencadeadas pelos indivíduos. Ao oferecer aos futuros professores as condições para elaborarem, pensarem, repensarem e analisarem as suas

Olh@ res, Guarulhos, v. 1, n1, p. 284-302, maio 2013. 
ações, favorece-se a criação de momentos de reflexão e síntese da organização do ensino que possibilitaram a objetivação das suas necessidades. Essa situação permitiu que o indivíduo reavaliasse os motivos que impulsionam e dirigem as suas ações como professor. Nesse sentido, concordo com Moretti (2007, p. 120) que os motivos foram se transformando e alguns novos surgiram à medida que as ações se estabeleceram significativamente para os indivíduos.

Nesse processo, as novas ações propostas visaram objetivar o novo motivo e, desta forma, passa haver a coincidência entre este e o produto objetivado. Assim, a organização do ensino, ao coincidir motivo e objeto, passa a constituir-se como atividade de ensino para o professor. Ao produzir novos motivos no decorrer da própria atividade, o professor também passa a atribuir novos sentidos a ela, o que inclui novos sentidos às suas ações, aos instrumentos que escolhe e ao processo de trabalho coletivo que criou condições para as mudanças percebidas.

Considerando a inserção de todos estes elementos na atividade dos estagiários, pode-se caracterizá-la da seguinte forma (figura 3).

\section{Instrumentos:}

elaboração e discussão da atividade de ensino

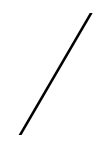

Sujeitos: os estagiários

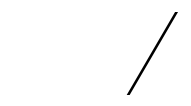

Regras:

responsabilidades como estagiários.

as expectativas de todos os participantes

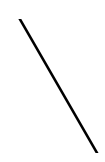

Comunidade:

PO; a equipe da escolacampo; os colegas da universidade; o corpo docente da universidade
Objeto: desenvolvimento de atividades de ensino que produzam uma aprendizagem significativa para os estudantes

\section{Divisão do trabalho:}

compartilhamento das ações com os demais estagiários e o PO
Resultados:

novo sentido para a atividade de ensino;

desenvolvimento de um trabalho colaborativo;

nova perspectiva para o conhecimento Iatemático;

Figura 3: A atividade dos estagiários

Olh@res, Guarulhos, v. 1, n1, p. 284-302, maio 2013. 
Neste sistema de atividade, os indivíduos do nosso sistema de atividade continuam sendo os estagiários. Contudo, agora os estudantes da escolacampo assim como os professores supervisores do estágio também compõem a nossa comunidade. Neste contexto, os estagiários se constituem em subgrupos que têm responsabilidades com a escola-campo. A divisão do trabalho nessa comunidade consiste no compartilhamento das ações entre os estagiários e entre Professor Orientador (PO).

As regras para a atividade dos indivíduos estão vinculadas a estas responsabilidades e às suas próprias expectativas com relação ao desenvolvimento das ações do estágio. Essas novas expectativas surgem com base na introdução de um novo instrumento, a atividade orientadora de ensino. Utilizando-se deste novo instrumento, ferramenta, os indivíduos foram capazes de dar uma nova qualidade ao objeto da sua atividade. Assim, a aprendizagem docente que era o objeto inicial da atividade dos indivíduos ganha outro significado; vincula-se à busca pela compreensão de uma forma de organização do ensino que permita que os indivíduos se apropriem dos conhecimentos inerentes a este processo. Em decorrência desta situação, as contradições iniciais entre a concretização do processo de aprendizagem docente e a limitação das ferramentas, bem como a realização das múltiplas atividades realizadas diariamente que competem com os objetivos pessoais de cada um dos estagiários são superadas. Isto se dá porque o objetivo das ações no estágio não compete com as demais atividades do indivíduo. Na verdade, elas contribuem para o seu processo de humanização e superação da alienação ao oferecerem como resultados a possibilidade da criação de um novo sentido para a atividade de ensino, do desenvolvimento do trabalho colaborativo e da apropriação de uma nova perspectiva para o conhecimento matemático.

A única tensão que ainda persiste na atividade é aquela que serve de móbil para o indivíduo, ou seja, a constante busca pela congruência entre as responsabilidades diárias do futuro professor e a satisfação em realizá-las.

Olh@ res, Guarulhos, v. 1, n1, p. 284-302, maio 2013. 
Este movimento indica a busca contínua do indivíduo pela realização do que se denomina atividade.

\section{Considerações finais}

Adequando-se as demandas por mudanças no processo de formação dos professores, o Estágio Supervisionado do Curso de Licenciatura em Matemática é concebido como um campo de conhecimento e tem como eixo principal: a pesquisa, vinculada ao desenvolvimento de projetos.

Os projetos e estudos apresentados neste trabalho tem como marca principal essa relação com a atividade de pesquisa. Com isto, espera-se que o processo de formação dos futuros professores de matemática se dê "no movimento que compreende os docentes como sujeitos que podem construir conhecimento sobre o ensinar na reflexão crítica sobre sua atividade, na dimensão coletiva e contextualizada" (PIMENTA; LIMA, 2004, p. 236).

Neste sentido, tem-se que pensar a formação do professor como um processo que restitui ao indivíduo o seu papel de agente histórico, o qual é capaz, por meio da sua atividade, de transformar tanto as condições objetivas do contexto real quanto transformar-se a si mesmo. Por conseguinte, deve-se pensar na aprendizagem da docência como um processo que ofereça a possibilidade dos sujeitos se tornarem aptos a viver a sua condição de seres humanos.

Decorre desta afirmação que teremos indivíduos, professores e estudantes, capazes de criarem novas perspectivas para as suas ações, que poderão leválos a serem homens universais e livres. E, ao considerarem a força, a complexidade e o limite imposto pelas condições objetivas, compreendam que, por meio da sua atividade, a atividade de ensino para o professor e a de aprendizagem para o estudante, conseguirão exercer o caráter universal inerente ao ser humano.

Olh@ res, Guarulhos, v. 1, n1, p. 284-302, maio 2013. 


\section{Referências Bibliográficas}

ALVES, D.; CEDRO, W. L.. Uma atividade orientadora de ensino: o problema deliano. Anais do IX ENEM. Recife, PE: SBEM, 2007.

ARAUJO, F. M.; RIBEIRO, H. I. C.; CEDRO, W. L.. Do lúdico ao sério: um caminho para o ensino do princípio fundamental da contagem. Anais do $\mathbf{X}$ Encontro paranaense de educação matemática, 2009.

BARREIRO, I.; GEBRAN, R. Prática de ensino e estágio supervisionado na formação de professores. São Paulo: Avercamp, 2006.

CABRAL, A.; CAMARGO, V.; CEDRO, W. L.. Brincar e aprender: uma experiência de ensino e aprendizagem no circo. In: LOPES, A.; PEREIRA, P. (Org.). Ensaios em educação matemática: algumas possibilidades para a educação básica. Campo Grande, MS: Editora UFMS, 2010.

O Lúdico no Ensino Médio: Possibilidade de Aprendizagem. ANAIS DO XIII CIAEM. Recife, PE, 2011.

CEDRO, W. O espaço de aprendizagem e a atividade de ensino: O Clube de Matemática. Dissertação (Mestrado em Educação) - Faculdade de Educação, Universidade de São Paulo, São Paulo, 2004.

FIORENTINI, D.; CASTRO, F. Tornando-se professor de matemática: o caso de Allan em prática de ensino e estágio supervisionado. In: FIORENTINI, D. Formação de professores de Matemática: explorando novos caminhos com outros olhares. Campinas, SP: Mercado de Letras, 2003.

LEONTIEV, A. O desenvolvimento do psiquismo. Lisboa: Horizonte Universitário, 1978. Actividad, conciencia, personalidad. Traducción Librada Leyva Soler, Rosario Bilbao Crespo e Jorge García. Habana: Editorial pueblo y educación. 1983.

LOPES, A. A aprendizagem docente no estágio compartilhado. Tese (Doutorado em Educação) - Faculdade de Educação, Universidade de São Paulo, São Paulo, 2004.

MORETTI, V. Professores de Matemática em Atividade de Ensino. Uma perspectiva histórico-cultural para a formação. Tese (Doutorado em Educação) - Faculdade de Educação, Universidade de São Paulo, São Paulo, 2007. 
MOURA, M. O educador matemático na coletividade de formação: uma experiência com a escola pública. Tese (Livre Docência em Metodologia do Ensino de Matemática) Faculdade de Educação. Universidade de São Paulo, São Paulo. 2000.

. (Org.). O estágio na formação compartilhada do professor: retratos de uma experiência. São Paulo: FEUSP, 1999.

OLIVEIRA, A. C. B.; SANTOS, D. M.; SILVA, D. A.; CEDRO, W. L.. Uma proposta de estágio no Clube de Matemática: enfocando grandezas e medidas. ANAIS DO X ENEM. Salvador: SBEM, 2010.

OLIVEIRA, R. Estágio supervisionado participativo na licenciatura em matemática, uma parceria escola-universidade: respostas e questões. Tese (Doutorado em Educação: Ensino de Ciências e Matemática) - Universidade de São Paulo, São Paulo, 2006.

PIMENTA, S. O estágio na formação de professores: unidade teoria e prática? São Paulo: Cortez, 2005.

PIMENTA, S.; LIMA, M. (Orgs.). Estágio e Docência. São Paulo: Cortez, 2004. (Coleção docência em formação. Série saberes pedagógicos).

RIBEIRO, A. G.; CEDRO, W. L. Brincando com os números naturais: uma experiência no clube de matemática. ANAIS DO III ENCONTRO GOIANO DE EDUCAÇÃO MATEMÁTICA. GOIÂNIA: SBEM/GO, 2011.

RIBEIRO, L.; COSTA, T.; CEDRO, W. L. Da língua materna à linguagem matemática: o ensino das equações do $1^{\circ}$ grau. Anais do IX ENEM. Recife, PE: SBEM, 2007.

SANTOS, N.; SOUZA, R.; CEDRO, W. L.. As medidas: uma experiência matemática no ensino fundamental. CD 1 dos Anais do XIV ENDIPE. Porto Alegre, RS: EDIPUCRS, 2008. SILVA, D. A.; SANTOS, D. M.; CEDRO, W. L.. Grandezas e medidas: uma experiência de ensino no clube de matemática. ANAIS DO V CIEM. Canoas, RS: ULBRA, 2010. p. 1-10.

UFG. Resolução CEPEC n. 802. Goiânia, 05/12/2006.

VYGOTSKY, L. Psicologia pedagógica - edição comentada. Guilhermo Blanck (org.). Trad. Claudia Schilling. Porto Alegre: Artmed. 2003.

WELLS, G. The role of dialogue in activity theory. Mind, culture and activity, California: Laboratory of comparative human cognition, 9(1), p. 43-66, 2002. 